\title{
Carta sobre a virtude e a felicidade ${ }^{1}$
}

\author{
Jean-Jacques Rousseau \\ Tradução e apresentação: \\ João Vitor Rebechi ${ }^{2}$
}

\section{Apresentação}

Em 2012, Jean Starobinski publicou o livro Accuser et Séduire. Essais sur Jean-Jacques Rousseau. Este livro, o último publicado e revisado pelo especialista francês, sobre a filosofia rousseauniana, traz no post-scriptum uma carta de Rousseau, que foi intitulada por Starobinski: La «Lettre sur la vertu», un texte oublié. Como o título sugere, não se trata de uma carta inédita, mas de uma carta, até então, pouco conhecida pelos pesquisadores. Com efeito, essa carta foi publicada pela primeira vez pelo editor Paul Streckeisen-Moultou, em 1861, sob o título Lettres sur la vertu et le bonheur. Nela, Rousseau, ilustre por seu método hipotético dedutivo com o qual reconstitui o primórdio da humanidade no Discurso sobre a origem e os fundamentos da desigualdade entre os homens, insiste mais sobre a ordem civil, como no Contrato social, e menos sobre o estado de natureza, a fim de responder como a virtude e a felicidade estariam ligadas a sociabilidade.

Ao citar "Shaftesbury e seu digno intérprete", Rousseau evoca a figura de Denis Diderot que havia traduzido para o francês, em 1745, o Ensaio sobre o mérito e a virtude do filósofo inglês, Shaftesbury. Contudo, em 1758 Rousseau rompe definitivamente a sua amizade com Diderot, pois, dentre outras coisas, ele havia lançado uma frase provocativa no Filho Natural, peça publicada em 1757, em que dizia que apenas o homem mau vive solitário. Ora, como se sabe, desde 1756 Rousseau havia deixado a capital francesa para se instalar em uma casinha no Ermitage. Ali, solitário em meio à natureza, o filósofo genebrino começou a escrever o romance epistolar Júlia ou a nova Heloísa, em que, por meio de suas personagens, coloca em situação os conflitos entre a virtude, a paixão e a sociedade. Assim, tendo em vista o assunto filosófico que essa carta reúne, é possível situar a sua redação entre os anos de 1755 e 1762, basta lembrar

\footnotetext{
${ }^{1}$ Lettres sur la vertu et le bonheur.

2 Área de formação: Filosofia. Subárea: subjetividade, arte e cultura. Titulação: Mestrando.

Instituição de Origem: Universidade Federal de São Paulo (UNIFESP).

Fomento: Coordenação de Aperfeiçoamento de Pessoal de Nível Superior (CAPES).

E-mail: joaovitor_rebechi@hotmail.com. Tradução recebida em 02/06/2020 e aceita em 18/07/2020.
} 
que, em 1755 Rousseau publicava o segundo Discurso, em 1761 a Nova Heloísa e em 1762 o Contrato social.

\section{Carta sobre a virtude e a felicidade}

Você procura mais me embaraçar que se instruir ao me perguntar o que é a virtude? Eu poderia lhe dizer em duas palavras o que é aquilo que ninguém pode aprender senão de si mesmo e que você não saberá jamais se seu coração não lhe responder antecipadamente. Ademais, por que retomar uma questão tão frequente e tão bem resolvida? Abra Platão, Cícero, Plutarco, Epiteto, Antonino Pio, consulte o virtuoso Shaftesbury e seu digno intérprete. Faça ainda melhor, estude a vida e os discursos do justo, medite sobre o Evangelho; ou antes, deixe todos os livros, volte-se a si mesmo, escute essa voz secreta que fala a todos os corações e seja virtuoso para saber aquilo que é próprio da virtude. Não creia, no entanto, que eu me recuso a este trabalho sublime com o qual você me honra. Eu sei que existem casos em que somos obrigados a empreender mais do que podemos executar, em que devemos consultar menos nossas forças do que o nosso dever; sobretudo, em um assunto importante para a sociedade, sei que, imediatamente quando questionado, ninguém pode recusar uma declaração de seus sentimentos. Não pense também que, impondo isso a mim mesmo, espero um grande sucesso de meus cuidados: vejo mais curiosidade do que zelo em sua pressa para me interrogar e sinto mais zelo do que luzes em meu ardor ao lhe responder. No entanto, o que eu não terei podido fazer por você, tentarei fazer por mim mesmo. Ora, conseguimos sair do estudo da virtude sem benefícios? Não, seus divinos efeitos são incompreensíveis, ela queima antes mesmo de esclarecer, nós a amamos assim que a procuramos, nós a sentimos antes que a conheçamos; e se minha razão pudesse se extraviar ao persegui-la, eu me consolaria facilmente de um erro que me tornasse um melhor homem de bem.

Não espere encontrar aqui dissertações metafísicas, nem todo este aparato de palavras que muitos leitores, sem dúvida, procurarão aqui, e que só serve para tornar o homem mais vaidoso, sem o tornar melhor nem mais esclarecido. Esta afetação de doutrina não serve nem ao autor nem à obra em uma matéria em que é mais questão de sentir do que perceber e que os mais simples entendem sempre melhor do que os mais sábios. A natureza deu-nos sentimentos, não luzes e, como não poderíamos, sem injustiça, nos interrogar sobre o que nós não recebemos, 
teríamos demasiado a nos lamentar se tanto conhecimento fosse necessário para conhecer a virtude.

Meu método será mais simples e mais seguro. Ao sondar minhas inclinações naturais, ouso pensar que elas são corretas, creio encontrar em meus desejos a imagem do homem de bem e não poderia melhor lhe dizer o que ele é do que lhe dizendo o que eu queria ser.

Queria, então, ter uma alma forte para sempre fazer o que é justo e sensível para sempre amar o que é belo: mas o que é a beleza, a sensibilidade, a justiça? E, o que é uma alma forte? Eis o que a mais sublime filosofia se empenha para nos explicar, ela explica bem menos para aqueles que procuram a verdade do que para aqueles que buscam a ciência. Contentemo-nos, então, em escutar a natureza; pois se a natureza bem consultada não pode sempre nos instruir, ao menos, ela jamais pode nos enganar.

Parece-me, primeiramente, que tudo o que existe de moral em mim tem sempre suas relações fora de mim, que eu não teria nem vícios nem virtudes se eu tivesse sempre vivido sozinho e que eu seria bom apenas desta bondade absoluta, que faz uma coisa ser aquilo que ela deve ser por sua natureza. Agora, também sinto que perdi essa bondade natural, como consequência de uma multiplicidade de relações artificiais, que são obras da sociedade e que me permitiram dar outras inclinações, outras necessidades, outros desejos, outros modos de as satisfazer, necessários à conservação de minha vida ou à constituição particular de minha pessoa, mas conforme aos fins particulares de que fui feito e às paixões factícias as quais me entreguei.

Segue-se daí, que é preciso me considerar, no entanto, como existindo de uma outra maneira e me apropriando, por assim dizer, de um outro tipo de bondade conveniente à esta nova existência. Hoje que minha vida, minha segurança, minha liberdade, minha felicidade dependem do concurso de meus semelhantes, é manifesto que eu não devo mais me ver como um ser individual e isolado, mas como parte de um todo maior, como membro de um maior corpo, de cuja conservação depende absolutamente a minha e que não seria mal ordenado, ainda que eu me sentisse em desordem. (Assim, a identidade da natureza, a fraqueza comum, as necessidades mútuas e a sociedade que as tornam necessárias, me dão os deveres e os direitos comuns a todos os homens). Eu pertenço a minha pátria, ao menos por minhas necessidades; minha pátria, por sua vez, pertence a qualquer outro país e todos estão submissos mais ou menos a esta dependência universal. Eis as verdades que nós sentimos mais que do que provamos e que eu me dispensaria de esclarecer se contasse tanto com sua boa-fé quanto com suas luzes. 
Você talvez me perguntará, se um homem que nada recebeu da sociedade poderia the dever qualquer coisa. Mas considere, eu lhe imploro, que uma tal suposição não é boa a ninguém quando ela reverte ao impossível; cada um vê que é de todo impossível que um homem nasça, viva e se conserve no seio da sociedade sem nada receber dela. Será em vão que alegará sua pobreza, seus males, seus infortúnios. O Estado lhe responderá: talvez fosse melhor para você ter nascido no fundo de um deserto; porém, você nasceu em meu seio, você viveu nele e não poderia ter sobrevivido se eu não lhe tivesse conservado; seria necessário deixar a vida, se ela lhe fosse uma carga demasiadamente pesada para carregar, ou o país, se as leis lhe parecessem duras demais; morra ou parta se você quiser, não me deve nada pelo devir, mas me dê o preço de trinta anos de vida que você gozou por minha assistência. Ainda que você não exista mais, me deve aquilo que você foi.

Não nos olhemos jamais como aqueles homens primitivos e imaginários que não tinham necessidade de ninguém, porque a natureza sozinha provia tudo. A natureza, por assim dizer, abandonou suas funções desde que nós as usurpamos. O homem social é por demais fraco para poder viver sem os outros, ele tem necessidade de tudo desde o instante de seu nascimento até aquele de sua morte, rico ou pobre ele não poderia subsistir sem receber nada de outrem.

Eu não devo, de modo algum, crer que estou separado de todo o mundo sob o pretexto de que os que me tem servido visam seu próprio prazer e seu próprio interesse: isto pode ser verdadeiro para os particulares, mas não para o corpo da sociedade, que visa a todos os seus membros e, por conseguinte, a você e a mim em tudo o que ele faz por ele mesmo. Assim, não é como particular que nós somos todos devedores uns dos outros, mas como membros da sociedade a qual cada um deve tudo. Além disso, o preço que todos pagamos à ajuda que recebemos é ele mesmo um dom da sociedade. Um homem poderia nada possuir sem o concurso e o consentimento dos outros? Sem este contrato tácito que eles fizeram, ele não teria nem ganho, nem propriedade, nem verdadeira indústria. No estado de natureza só existe o necessário, tudo de supérfluo que vemos entre nós não é a soma dos trabalhos dos particulares, mas o produto da indústria geral que faz, com cem braços agindo em concerto, mais do que cem homens não poderiam fazer separadamente.

Você me falará, eu o prevejo, da desordem do estado social, em que o bem público serve de pretexto a tanto mal, porém, é preciso distinguir a ordem civil de seus abusos e, do fato de que nem todos devolvem à sociedade o que lhe devem, não podemos concluir que nós não lhe devemos nada. Não é a ela que nós precisamos responsabilizar se, não fazendo nada do que ela 
nos ordena, nós nos tornamos infelizes em lhe ofender. Ademais, sob o império da opinião, quantas precauções deveríamos tomar para distinguir na avaliação das coisas a aparência da realidade! Quantos males nos parecem horripilantes e que não são nada por si mesmos, quantos homens queixam-se de seus destinos sendo que poderiam ser felizes sem mudar de estado e lamentam pelo motivo bem mais que pela fortuna! Tal rico pensa estar arruinado quando não lhe resta o bem do qual necessita e crê morrer de fome se lhes for necessário caçar um parasita. Uma prova de que muitos infortúnios são, em grande parte, imaginários, é que a mesma condição, tal como ela é, faz o desespero daquele que assim se encontra e a felicidade de cem outros. Não se compara jamais o que se é, nem à suas necessidades nem ao estado de outro, mas aquilo que se era ou aquilo que se gostaria de ser. A ambição conta sempre como nada o que ela adquire e como tudo o que lhe escapa.

Mas, o que temos incontestavelmente em harmonia no gênero humano é a vantagem, infinitamente superior a todos os bens físicos, de chegar pela comunicação de ideias e o progresso da razão até as regiões intelectuais; de adquirir as noções sublimes de ordem, de sabedoria e de bondade moral; de nutrir nossos sentimentos com o fruto de nossos conhecimentos; de nos elevar pela grandeza da alma acima das fraquezas da natureza; de nos comparar, em certos níveis, pela arte do raciocínio às inteligências celestes; enfim, de poder, pela força de combater e vencer nossas paixões, dominar o homem e imitar a divindade mesma. Assim, esse comércio contínuo de troca, de cuidado, de ajuda e de instrução nos sustenta quando não podemos mais nos sustentar por nós mesmos; esclarece quando temos a necessidade de ser esclarecidos, colocando em nosso poder bens de um preço inestimável que nos fazem desprezar o que não temos mais. Eis as verdadeiras compensações que consolam um homem honesto, no seio dos infortúnios, das perdas da natureza e dos abusos da sociedade. O antigo vigor dos membros é transposto para as faculdades, a razão cresce sobre as ruinas de um corpo débil, ao se dar esses entraves à liberdade, o coração adquire um novo império; ele obedece a voz do mais forte, mas comanda a suas paixões e, enquanto for oprimido aqui em baixo, sua alma pura se eleva até a morada celestial e goza do preço de sua virtude. É Hércules que sente de uma só vez queimar sua pira fúnebre e se tornar Deus.

Deste modo, o bem e o mal fluem da mesma fonte, mas a medida não é igual para todos. Ainda que atormentado pelos maus, o sábio sente, contudo, que ele não seria mais que um bruto se não tivesse recebido nada de ninguém e existem poucos males que possam enfraquecer, em um homem corajoso, os dons da alma e a esperança de bens futuros. 
Queremos agora buscar o que nos torna felizes neste mundo? Voltemo-nos sobre nós mesmos e consultemos nossos corações. Cada um sentirá que a felicidade não está nele, mas que ela depende de tudo o que o envolve. O luxo que ressalta toda a natureza, a ambição que quer concatenar o universo, a volúpia que não é nada na solidão, a vaidade que busca todos os olhos, a bondade que gostaria que todos fossem contentes, tudo o que nos interessa se prende a objetos estrangeiros, todos os nossos desejos sempre alçam voo, a felicidade que nos atribuem é a única que nós gozamos e nós preferíamos não existir do que não sermos olhados. Em uma palavra, seja a necessidade de amar, seja o desejo de agradar, seja a amizade, seja a confiança ou o orgulho, o hábito de nos relacionarmos com os outros torna em nós tão necessário este comércio, que nós não poderíamos duvidar que, se encontrássemos um só homem que visse mais do que todos os seus sonhos realizados, esteja seguro que, ao mesmo tempo, ele jamais veria seu semelhante sem cair em desespero.

Tais sãos os laços indissolúveis que nos unem a todos, dos quais dependem nossa existência, nossa conservação, nossas luzes, nossa fortuna, nossa felicidade e geralmente todos os nossos bens e todos os nossos males, das relações sociais. Creio, então, que ao me tornar um homem civil eu contraí um débito imenso com o gênero humano, que minha vida e todas as suas comodidades que dela usufruo devem ser consagradas a seu serviço. Vejo, ademais, que se eu procurasse obter uma espécie de bem-estar exclusivo e alguns prazeres duvidosos ao sacrificar tudo a mim mesmo, eu não poderia me assegurar um estado de paz e uma felicidade duradoura senão em uma sociedade bem ordenada. Vejo que se não respeito o direito dos outros que quero que respeitem em mim, me torno o inimigo comum de todos e não terei outra segurança na iníqua possessão de meus bens, senão aquela dos bandidos que devoram em suas cavernas os restos dos desafortunados. Este dever sagrado que a razão me obriga a reconhecer não é propriamente um dever de particular a particular, mas geral e comum como o direito que me impôs. Pois, os indivíduos a quem devo a vida, aqueles que me forneceram o necessário, aqueles que cultivaram a minha alma e aqueles que me comunicaram seus talentos podem não existir mais, mas as leis que protegeram minha infância não morrem jamais. Os bons costumes dos quais recebi hábitos felizes, as ajudas que encontrei diante da necessidade, a liberdade civil que eu desfrutei, todos os bens que eu adquiri, todos os prazeres que eu provei, eu os devo a esta polícia universal que dirige os cuidados públicos para a comodidade de todos os homens, que previa minhas necessidades antes de meu nascimento e que fará respeitar minhas cinzas depois de minha morte. Assim, meus benfeitores podem morrer, mas, enquanto existirem homens, sou obrigado a restituir a humanidade os benefícios que dela recebi. 


\section{Referências Bibliográficas}

\section{Obras de Jean-Jacques Rousseau}

ROUSSEAU, Jean-Jacques. Lettre sur la vertu et le bonheur. Texto estabelecido por Jean Starobinski. In: STAROBINSKI, Jean. Acuser et séduire. Essais sur Jean-Jacques Rousseau. Paris : Gallimard, 2012, p. 309-316.

. Julie ou la Nouvelle Héloüse. Oeuvres Completes (O.C.). Paris : Gallimard, « Bibliothèque de la Pléiade », t. II, 1961.

. Júlia, ou, A Nova Heloísa. São Paulo: Editora de Humanismo, Ciência e tecnologia HUCITEC em coedição com a Universidade Estadual de Campinas UNICAMP, 1994.

Emílio, ou, da educação. São Paulo: Martins Fontes, 2014.

. Discurso sobre as ciências e as artes. São Paulo: Nova Cultural, 1999.

. Discurso sobre a origem e os fundamentos da desigualdade entre os homens. São Paulo: Nova Cultural, 1999.

. Do contrato social. São Paulo: Nova Cultural, 1999.

Ensaio sobre a origem das línguas. Campinas: Editora da Unicamp, 2008.

Carta a d'Alembert sobre os espetáculos. Campinas, SP: Editora Unicamp, 2015.

Idée de la méthode dans la composition d'un livre. In: Oeuvres Completes, t. II. Paris :

Gallimard, «Bibliothèque de la Pléiade », 1961.

\section{Bibliografia Geral}

CASSIRER, Ernst. A questão Jean-Jacques Rousseau. São Paulo: Editora Unesp, 1999.

DERATHÉ, Robert. O racionalismo de Jean-Jacques Rousseau. In: Cadernos de Educação, no 41,2013

FORTES, Luiz Roberto Salinas. Rousseau: o bom selvagem. São Paulo: FTD, 1989.

PRADO Junior, Bento, A retórica de Rousseau e outros escritos. São Paulo: Editora Unesp, 2018.

STAROBINSKI, Jean. Jean-Jacques Rousseau a transparência e o obstáculo. São Paulo: Companhia das Letras, 2011. 